\title{
Efficacy of Diffusion-Weighted MRI in Thyroid Nodules
}

\author{
HOSSAM EL-DIN GALAL MOHAMMAD, M.D.*; MOSTAFA Th. HUSSEN, M.D.*; \\ REHAM S. SAYED, M.Sc.*; MARWA I. ABDELGAWAD, M.D.** and GEHAN S. SEIFELDEIN, M.D.* \\ The Departments of Diagnostic Radiology* and Clinical Oncology**, Faculty of Medicine, Assiut University
}

\begin{abstract}
Background: Differentiation of benign from malignant thyroid nodules remains a challenge. Diffusion-weighted magnetic resonance imaging is a recent non-invasive imaging can differentiate between benign and malignant lesions.

Aim of Study: Evaluate the efficacy of Diffusion-Weighted Magnetic Resonance Imaging (DW-MRI) in discrmination between benign and malignant thyroid nodules comparing the results of Apparent Diffusion Coefficient (ADC) value with histopathological results.
\end{abstract}

Material and Methods: This case-control study included 30 patients with solitary (dominant solid or mixed solid and cystic) thyroid nodules on the basis of ultras ono graphic examination (US) and 10 persons with normal thyroid of matching age and sex. All were subjected to clinical assessment, radiological assessment included thyroid US, color Doppler examination and conventional non contrast MRI, DWI and ADC maps were obtained. ADC values of each nodule were correlated with histopathological results.

Results: The cut-off value for the differentiation of benign from malignant thyroid nodules, was $1.3 \times 10^{-3} \mathrm{~mm} / \mathrm{s}$ with mean of $\left(1.39 \pm 0,11 \times 10^{-3} \mathrm{~mm} / \mathrm{s}\right)$ for benign nodules and $\left(0.81 \pm 0.17 \times 10^{-3} \mathrm{~mm} / \mathrm{s}\right)$ for malignant ones with the sensitivity and specificity are $100 \%$ and $88.9 \%$ respectively. The overall accuracy is $95 \%$.

Conclusion: Preliminary results showed that DW-MRI provides very useful and promising imaging to evaluate the nature of a thyroid nodule and in discrmination between benign and malignant nodules.

Key Words: Diffusion-Weighted Magnetic Resonance Images (DW-MRI) - Apparent Diffusion Coefficient (ADC) value - Thyroid nodules.

\section{Introduction}

THYROID nodules are the commonest disorder of the thyroid gland. Palpable thyroid nodules are seen in $5 \%$ of the population with normal iodine intake, while the incidence increased up to two to

Correspondence to: Dr. Hossam El-Din Galal Mohammad, The Department of Diagnostic Radiology, Faculty of Medicine, Assiut University three times in people living in regions suffering from iodine deficiency. The frequency of malignancy in the thyroid gland is relatively low: Only $5 \%$ of these nodules are malignant [1].

Firm thyroidal mass, airway compression, dysphagia, hoarseness, and cervical lymphadenopathy are strong indicators of a thyroid malignancy. But this classical clinical presentation is generally not seen in most of the patients with thyroid carcinoma, so the differential diagnosis of thyroid nodules requires additional diagnostic methods in addition to the clinical examination [2].

Clinical examination, ultrasonography (US), isotope scans, and Fine-Needle Aspiration Cytology (FNAC) are the common methods to evaluate thyroidal nodularities. Sonography-guided FNAC (USgFNAC) is a worldwide established technique that provides further evaluation of the nodules on a cytologic level [3,4].

Indeterminate cytologic findings by USgFNAC demand the addition of diagnostic methods and, if necessary, surgery [5]. USgFNAC is an invasive procedure and uncomfortable for patients. Therefore, there is a demand for both noninvasive and more accurate diagnostic methods for further evaluation of thyroid nodules [6-9].

Thyroid nodules are often an incidental finding on MR images. Therefore, the addition of a DW sequence in equivocal cases has the potential to prevent unnecessary additional examinations for treatment.

Diffusion-Weighted Imaging (DWI) is one of the functional MRI modalities, which allows quantitative measurement of water molecules motion in lesions and normal tissues. The net diffusion of water molecules is referred to as the Apparent Diffusion Coefficient (ADC) [10] 


\section{Aim of study:}

The aim of the current study was to evaluate the efficacy of Diffusion-Weighted Magnetic Resonance Imaging (DW-MRI) in discrmination between of benign and malignant thyroid nodules comparing the results of Apparent Diffusion Coefficient (ADC) value with histopathological results.

\section{Patients and Methods}

From December 2015 to May 2018, a prospective study was conducted upon 30 patients with solitary or dominant thyroid nodule on the basis of ultrasonography examination. Twenty five were females and five were males with 40 thyroid nodules. Their ages ranged from 25 to 65 years with mean age $47 \pm 13.8$ years. Clinically neck swelling was the most common presenting symptom in $70 \%$ of patients. Other symptoms included dyspnea, dysphagia, and hoarseness of voice that presented in $30 \%$ of patients and irritability and weight loss in $10 \%$ of patients. Ten healthy individuals were included in the study as control who were sex and age-matched. Patients were referred from General Surgery, General Medicine, and Clinical Oncology Departments to Radio-Diagnosis Department, Assiut University Hospital for conventional noncontrast MRI and thyroid MRI diffusion examinations. Approval of our institutional Research Ethics Committee and informed consent from all patients were obtained.

\section{Inclusion criteria:}

Patients in different age groups with solitary or dominant thyroid nodule(s), solid or mixed (solid and cystic) undergone ultrasound examination prior to the surgery or FNAB and histopathological examination of the nodules post-operatively.

\section{Exclusion criteria:}

1- Any general contraindication of MRI e.g. pacemakers.

2- Severely ill patients or those with claustrophobia.

3- Patients with multiple thyroid nodules (not solitary or dominant).

4- Patients with the totally cystic nodule.

5- Patients with hyperthyroidism.

Method:

The patients were subjected to the following:

\section{Clinical assessment:}

Including full clinical history and examination and laboratory tests including thyroid function tests.

\section{Imaging assessment:}

Thyroid US and Color Doppler examination which was performed by the superficial linear probe (frequency $7.5-11 \mathrm{MHz}$ ) using ultrasound system (GE, logic 3). Each nodule was scored for categorizing nodules on TI-RADS (Thyroid Imaging Reporting and Data System) classification [11]

Conventional non-contrast Magnetic Resonance (MR) imaging preliminary to the Diffusionweighted Imaging (DWI) examination. It was performed at 1.5T superconducting MR imager (Achieva, Philips Medical Systems, Netherland B.V.). Patients were positioned in the supine position and were instructed not to swallow or move during the examination. The examination was done by using a neck circular polarization surface coil with a small field of view and thin sections.

\section{MRI protocols include:}

1- Sagittal spin echo set of images is obtained initially to determine the location of axial images.

2- Thin (2-4mm) axial Tl-weighted (a repetition time (TR) of 500-600ms and echo time (TE) of $8-9 \mathrm{~ms}$ ) images, and T2-weighted (TR of $3000 \mathrm{~ms}$ and TE of 100ms) images with intersection gap $1 \mathrm{~mm}$. Field of view (FOV) is usually 220 to $250 \mathrm{~mm}$ with a matrix of $256 \times 256$ for axial images. Axial TI \& T2 images extended from hyoid bone (approximately the level of the third cervical vertebra) to the lung apex.

3- Coronal T2 \& SPIR images were obtained for evaluation of masses that extended below the cervico-thoracic Junction.

\section{Thyroid diffusion MRI:}

DWI which was obtained in the axial plane and it was obtained using a multi-section single shot spin echoplanar (EPI) sequence (TR/TE/NEX: $3395 / 100 \mathrm{~ms} / \mathrm{l}$ ) with diffusion sensitivities of $b$ values $400,600,800$ and $1000 \mathrm{~s} / \mathrm{mm}^{2}$. The diffusion gradients were applied sequentially in the three orthogonal directions. Sections of 2-4mm thickness, an inter-slice gap of $1 \mathrm{~mm}$, a $230-255 \mathrm{~mm}$ FOV and a $256 \times 256$ matrix were used with an average scan time of 3.5 minutes.

ADC maps were formed automatically, a circular Regions of Interest (ROI) ranging from 10 to $40 \mathrm{~mm}$ according to the size of the nodule, were placed in the center of the lesion in cases of solid nodules and on the solid portion of the lesion in cases of mixed solid-cystic thyroid nodules. The $\mathrm{ADC}$ values are expressed in square millimeters per second. 


\section{Cytology and histopathological examination:}

Cytology and histopathological examination were considered the gold standard and all patients underwent an examination either by US-guided Fine Needle Aspiration (FNA) cytology or postsurgical histopathological examination.

\section{Statistical analysis:}

Statistical analysis was done by SPSS Version 16. The variables were presented as a mean and standard deviation and numbers (percentage). The comparison was done by $t$-test. The sensitivity and the specificity of DWI were calculated. The probability ( $p$-value) was considered significant when $(p<0.05)$.

\section{Results}

According to US examinations $80 \%$ of solitary or dominant thyroid nodules were located in right thyroid lobe and their ultrasound patterns were be listed in (Table 1). The most of malignant nodules (63.6\%) appeared as hypoechoic lesions and most of the benign nodules $(44.44 \%)$ appeared as an isoechoic lesion. The most benign thyroid nodules $(77.7 \%)$ had sharp and well-defined margins, whereas the malignant nodules $(54.54 \%)$ had irregular and poorly defined margins. Most of the benign nodules $(55.55 \%)$ were associated with a halo sign, whereas only $18.18 \%$ of malignant nodules were associated with a halo sign. The coarse, large and multiple calcifications were characteristic for benign nodules, while fine and punctate internal calcifications were characteristic for malignant nodules, especially for papillary carcinoma. Based on their ultrasound pattern, 8 (20\%) thyroid nodules had score of 3 and classified as TI-RADS 3, 6 (15\%) nodules had a score of 4 and classified as TI-RADS 4 and the remaining $26(65 \%)$ nodules had a score of 5 and higher and they were classified as TI-RADS 5. All of the benign nodules show peripheral flow pattern (type II) while most of the malignant nodules $(72.72 \%)$ show internal flow pattern (type III) Figs. $(1,2)$.

MRI findings of the thyroid nodules showed increased intensity at T2-weighted images. Benign nodules showed faint restriction with mean $\mathrm{ADC}$ values ranged between $1.3-1.7 \times 10^{-3} \mathrm{~mm} / \mathrm{sec}$., malignant nodules showed areas of intense restriction in all $b$-values with a range of ADC values between 0.4-1 X 10 $\mathrm{mm}^{-3} / \mathrm{s}$ Figs. $(1,2)$.

The cut-off value for the differentiation of benign from malignant thyroid nodules was $1.3 \mathrm{X}$
$10^{-3} \mathrm{~mm}^{2} / \mathrm{s}$ with a mean of $\left(1.39 \pm 0.11 \times 10_{-3}^{-3} \mathrm{~mm}_{2}^{2} / \mathrm{s}\right)$ for benign nodules and $\left(0.81 \pm 0.17 \times 10^{-3} \mathrm{~mm}^{2} / \mathrm{s}\right)$ for malignant ones with the sensitivity, and specificity is $100 \%$, and $88.9 \%$ respectively. The overall accuracy was $95 \%$ Fig. (3).

Regarding the control group, normal thyroid tissue had ADC values ranged between 1.3-1.6 X $10^{-3} \mathrm{~mm}_{2}^{2} / \mathrm{s}$ and the mean value was $1.61 \pm 0.26 \mathrm{X}$ $10^{-3} \mathrm{~mm}^{2} / \mathrm{s}$.

Table (2) showed significant differences in $\mathrm{ADC}$ values between benign and malignant nodules and among ADC values of benign and malignant thyroid nodules and normal-appearing thyroid parenchyma of healthy subjects.

Histopathological studies, FNAC was done for all cases, but it was inconclusive in 3 cases. Trucut needle or postsurgical biopsy was done for 7 cases including these 3 cases who their FNAC was inconclusive. The most common benign lesion was adenomatous hyperplasia (6 nodules were adenoma, 4 nodules were simple nodular goiter and 8 nodules were adenomatoid nodules) while the most common malignant lesions were papillary adenocarcinoma and follicular carcinoma ( 8 nodules were papillary thyroid carcinoma, 8 nodules were follicular thyroid carcinoma, 4 nodules were medullary thyroid carcinoma and 2 nodule was anaplastic carcinoma).

Table (1): Gray-scale Ultrasound and color Doppler features of thyroid nodules in 20 studied thyroid nodules.

\begin{tabular}{|c|c|c|}
\hline US parameter & $\begin{array}{l}\text { Benign } \\
\text { nodules } \\
(n=18)\end{array}$ & $\begin{array}{c}\text { Malignant } \\
\text { nodules } \\
(n=22)\end{array}$ \\
\hline Size $(\mathrm{mm})$ & $28.33 \pm 17.51$ & $42.45 \pm 19.15$ \\
\hline \multicolumn{3}{|l|}{ Echo pattern: } \\
\hline Hypoechogenicity & $4(22.22 \%)$ & $14(63.6 \%)$ \\
\hline Hyperechogenicity & $6(33.33 \%)$ & $6 \quad(27.3 \%)$ \\
\hline Isoechogenicity & $8(44.44 \%)$ & $2(9.1 \%)$ \\
\hline \multicolumn{3}{|l|}{ Margin of nodule: } \\
\hline Regular & $14(77.77 \%)$ & $10(45.45 \%)$ \\
\hline Irregular & $4 \quad(22.2 \%)$ & $12(54.54 \%)$ \\
\hline Halo sign & $10(55.55 \%)$ & $8 \quad(18.18 \%)$ \\
\hline Calcification & $10(55.5 \%)$ & $8 \quad(36.36 \%)$ \\
\hline $\begin{array}{l}\text { Presence of cervical LNs } \\
\text { have malignant US patterns }\end{array}$ & $0(0 \%)$ & $10(45.45 \%)$ \\
\hline \multicolumn{3}{|l|}{ Grade of color doppler: } \\
\hline Type I & $0(0 \%)$ & $0(0 \%)$ \\
\hline Type II & $18(100 \%)$ & $6 \quad(27.27 \%)$ \\
\hline Type III & $0(0 \%)$ & $16(72.72 \%)$ \\
\hline
\end{tabular}




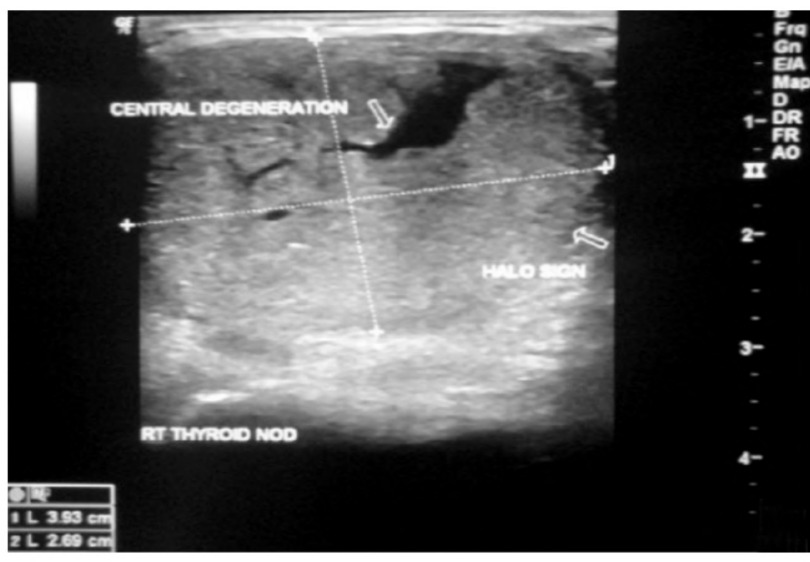

(A)

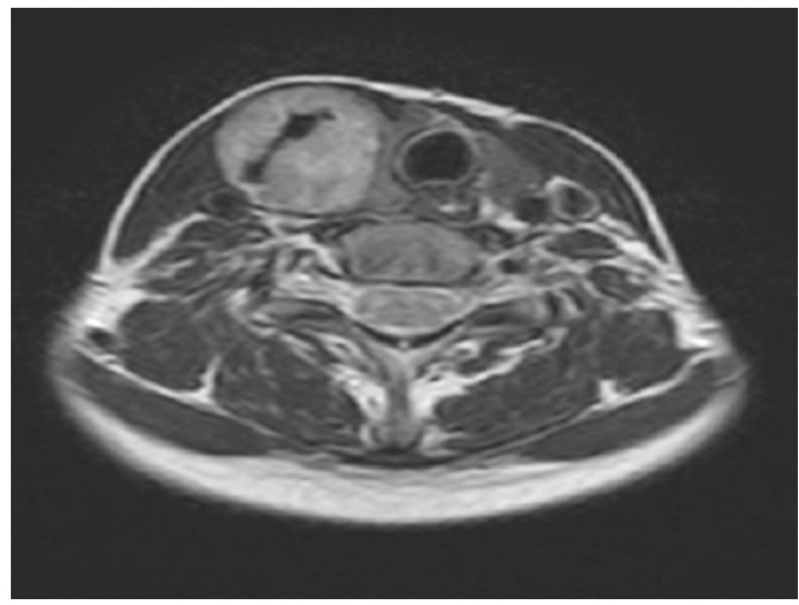

(C)

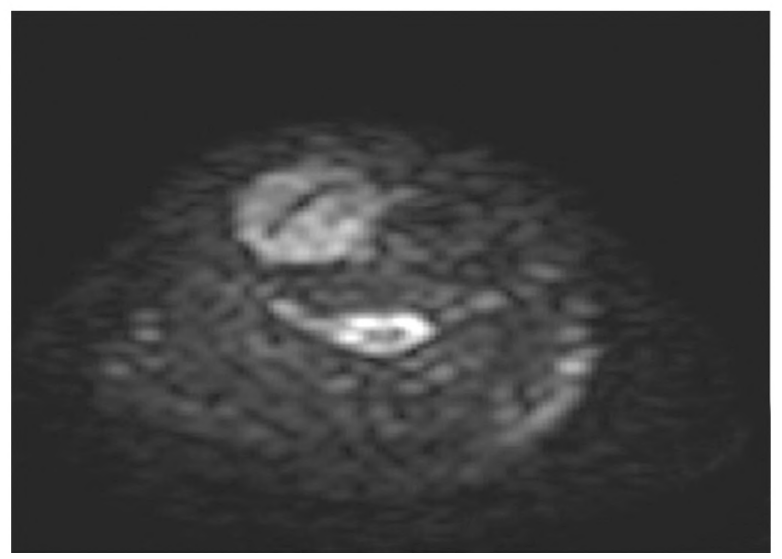

(E)

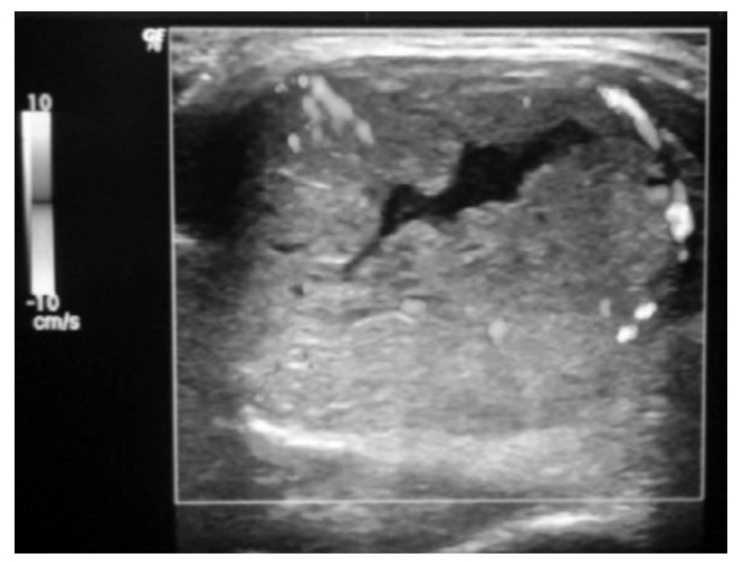

(B)

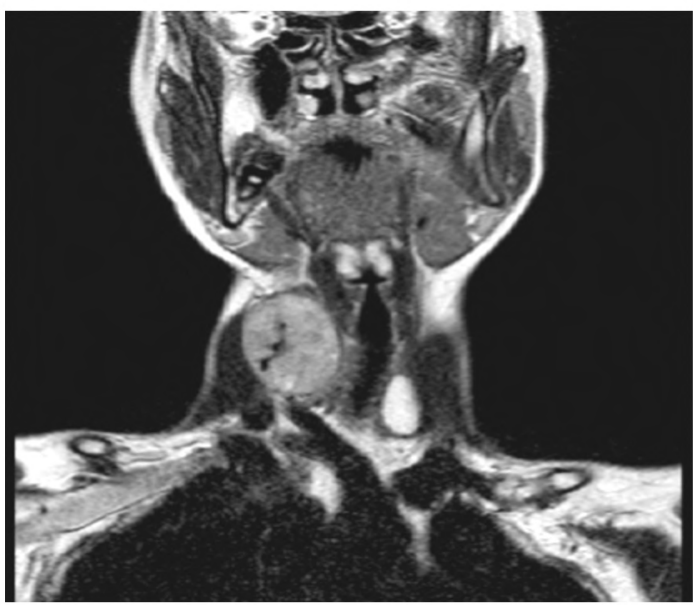

(D)

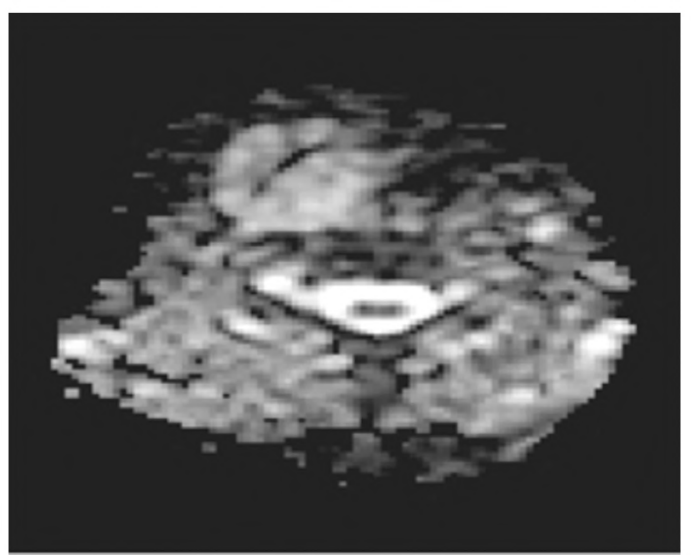

(F)

Fig. (1): (A-F): A 25-years old female presented by neck swelling with irritability and weight loss: US examination (A-B) Shows large right isooechoic nodule with central branching anechoic degeneration inside. Doppler US shows perinodular vascularity type II. MRI examination (C-F) C: Axial Tl WI, nodule has hyperintense signal with central signal void branching area. D: Coronal T2WI, right nodule shows hyperintense signal \& another left lower polar hyperintense cystic lesion. E: DWI shows areas of restriction within right lobe nodule. F: ADC map with measured value within restricted areas was ranged between 1.3-1.6 X $10^{-3} \mathrm{~mm} / \mathrm{s}$. Pathological examination (FNAC/biopsy) revealed benign thyroid adenoma. 

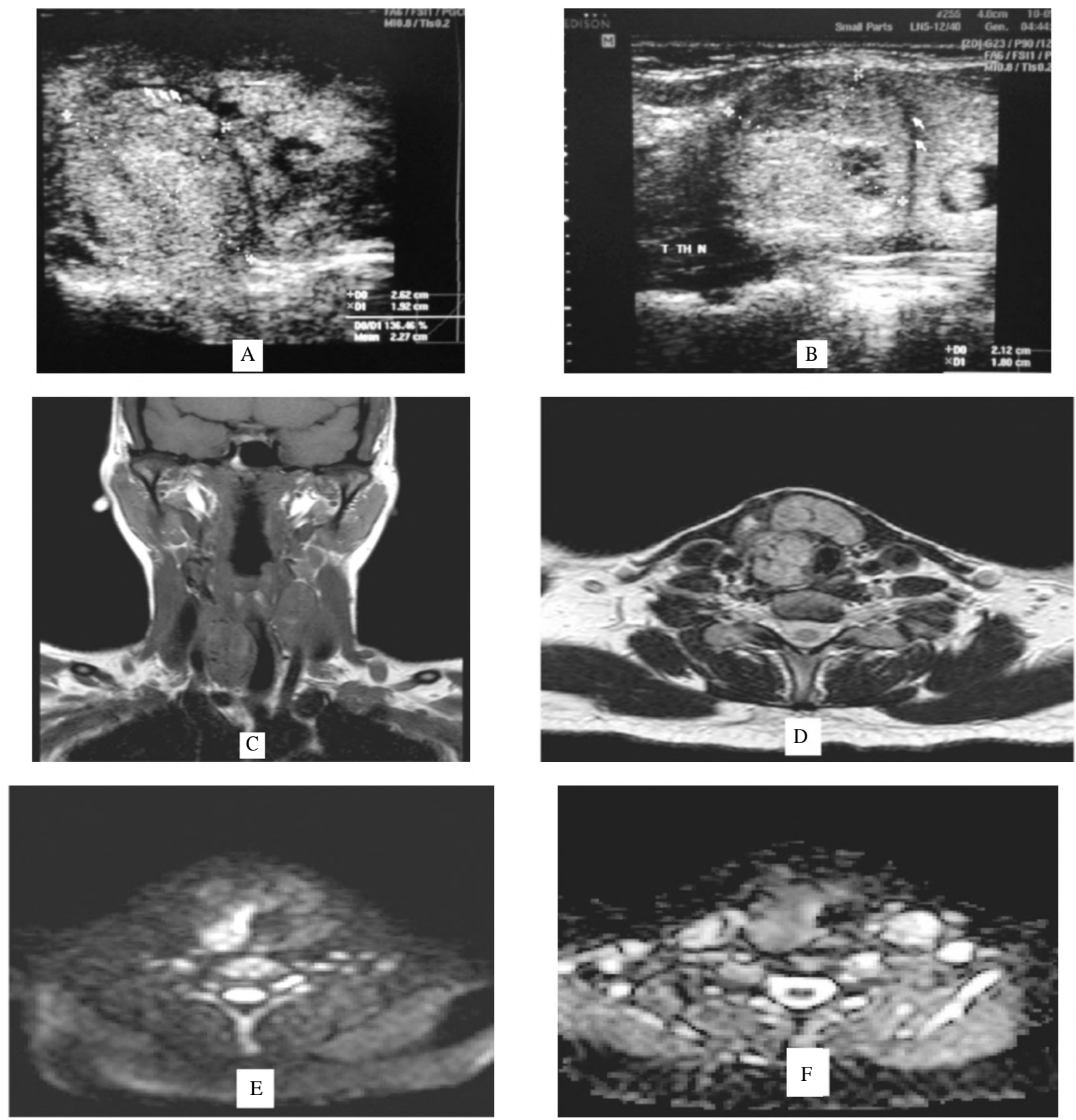

Fig. (2): (A-F): A 29-years old female presented by neck swelling and hoarseness of voice. A \& B: US examination shows large right heterogeneous echogenicity nodule with incomplete halo sign around with areas of cystic degeneration inside. MRI examination (C, D); C: Coronal Tl WI, shows bilateral nodules with slightly hypointense signal. D: Axial T2WI, right \& isthmic nodules shows hyperintense signal. E: DWI showzs areas of restriction within right nodule. F: ADC map with measured value within restricted areas of $0.9 \times 10^{-3} \mathrm{~mm} / \mathrm{s}$. Pathological examination (FNAC/biopsy) reveled multicenteric follicular variant of papillary carcinoma in back ground of adenomatous goiter.

Table (2): Mean ADC of thyroid nodules in studied population.

\begin{tabular}{lcccccc}
\hline & $\begin{array}{c}\text { Malignant } \\
(\mathrm{n}=11)\end{array}$ & $\begin{array}{c}\text { Benign } \\
(\mathrm{n}=9)\end{array}$ & $\begin{array}{c}\text { Control } \\
(\mathrm{n}=10)\end{array}$ & $p_{1}$ & $p_{2}$ & $p_{3}$ \\
\hline $\begin{array}{l}\mathrm{ADC}(\mathrm{Mean} \pm \mathrm{SD}) \\
\mathrm{X} 10 \quad \mathrm{~mm} / \mathrm{s}\end{array}$ & $0.81 \pm 0.166$ & $1.39 \pm 0.113$ & $1.60 \pm 0.258$ & $<0.0001 * *$ & $.036^{*}$ & $<0.0001 * *$ \\
\hline$* p<0.05$. & $* *: p<0.001$. \\
$p 1$ difference between malignant and being. & $\begin{array}{l}p 2 \text { difference between benign and control. } \\
p 3 \text { difference between malignant and control. }\end{array}$
\end{tabular}




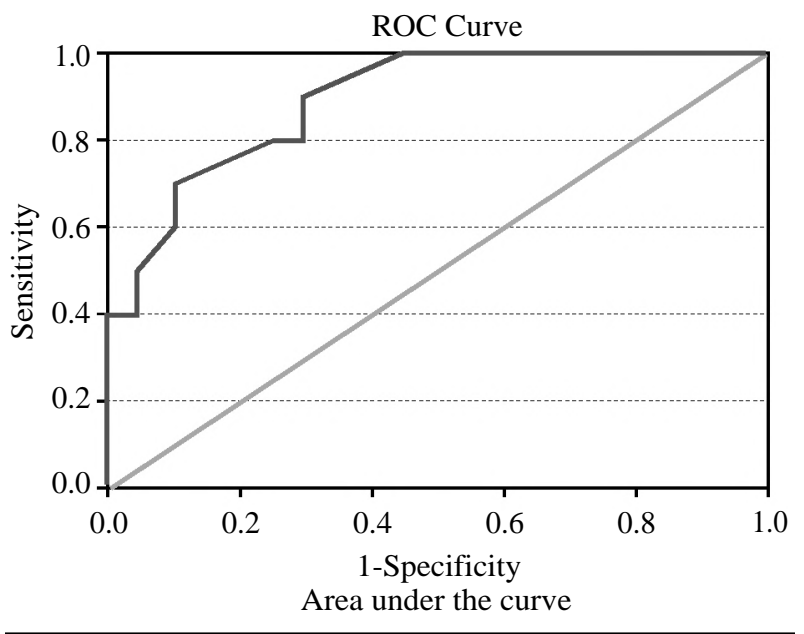

\begin{tabular}{ccccc}
\hline & \multirow{2}{*}{$\begin{array}{c}\text { Std. } \\
\text { Area }\end{array}$} & $\begin{array}{c}\text { Asymptotic } \\
\text { Errora }\end{array}$ & $\begin{array}{c}\text { Asymptotic 95\% } \\
\text { Sig.b }\end{array}$ & \multicolumn{2}{c}{\begin{tabular}{c} 
Confidence Interval \\
\cline { 3 - 4 }
\end{tabular}} & & Lower Bound & Upper Bound \\
\hline 893 & .058 & .001 & .779 & 1.000 \\
\hline
\end{tabular}

Fig. (3): ROC of cut off value of ADC for differentiation between benign and malignant thyroid nodules.

\section{Discussion}

In this study, all proved malignant nodules have confined areas in diffusion-weighted imaging until excessive $b$-values and occasional ADC values. These are constant with Kim et al. [12], and are concept to be due to mobile membranes impeding the mobility of water protons. Also, our consequences are matching with Gupta, et al. [13], who cited that maximum cancers is characterized by excessive cellularity and consequently a restriction of water diffusion. The boom of cellularity in tumors, restriction of intercellular distance, and the diffusion of water from extracellular media into the intracellular place can be liable for the low ADC values in tumors.

In two cases with sizable metastatic cervical lymphadenopathy, restricted diffusion with low ADC values is noted. In contrast to that, in patients with head and neck cancer, metastatic cervical lymph nodes had a significantly higher ADC than those with benign nodes. This discrepancy can be explained, as squamous cell carcinomas tend to be partially necrotic and therefore to have a higher ADC [14]. Also, the use of DW-MRI in discriminating between benign and malignant ovarian tumors has been disappointing due to prominent cystic components in this pathology [15]. For this reason, the cystic or necrotic parts of the tumors were not measured in our study due to giving fallacies with high ADC values and false negative results.
We used $b$-value of 200, 400, 800 and 1000s/ $\mathrm{mm}^{2}$ in the start, however, later using b-value higher than 800 produced better quality images and so better results. The mean ADC values of thyroid nodules done by b-800-1000 were (1.39 \pm $\left.0.11 \times 10^{-3} \mathrm{~mm}^{2} / \mathrm{s}\right)$ in the benign group and $(0.81 \pm$ $0.17 \times 10^{-3} \mathrm{~mm}^{2} / \mathrm{s}$ ) in the malignant group. In the control group, normal thyroid tissues had a range of ADC values of $1.30-2 \times 10^{-3} \mathrm{~mm} / \mathrm{s}$.

Bozgeyik et al. [16] reported that mean ADC values for malignant and benign nodules to be $0.56 \pm 0.43 \times 10^{-9}$ and $1.80 \pm 0.60 \times 10_{-3}^{-3} \mathrm{~mm}^{2} / \mathrm{s}$ for b- $200_{-3}$ and $0.30 \pm 0.20 \times 10^{-3} \mathrm{~mm} / \mathrm{s}$ and $1.15 \pm 0.43$ $X 10^{-3} \mathrm{~mm} / \mathrm{s}$, for b-300. Although there are statistically significant lower ADC values in malignant nodules, the differences between the DWI values might be the result of different imaging parameters (b-factors).

On the other hand, Erdem et al. [10], used b values of 0 and 1000 , they found an $\mathrm{ADC}_{2}$ value for benign nodules of $2.74 \pm 0.60 \times 10^{-3} \mathrm{~mm}^{2} / \mathrm{s}$ and that for malignant nodules of $0.695 \pm 0.312 \times 10^{-3}$ $\mathrm{mm}^{2} / \mathrm{s}$. In the current study, ADC values for benign nodules were lower than their results. But, our $\mathrm{ADC}$ values for malignant nodules were higher.

While Mutlu et al. [17], in their study used b values of $0,50,400$ and $1000 / \mathrm{mm}^{2}$, found a statistically significant relationship between nodule histopathology and nodule ADC values. Mean ADC values are determined as $1.6 \pm 0.1 \times 10^{-3}$ $\mathrm{mm}^{2} / \mathrm{s}$ for benign and $0.8 \pm 0.2 \times 10^{-3} \mathrm{~mm}^{2} / \mathrm{s}$ for malignant lesions. According to these results, it is observed that the ADC values in benign nodules are higher when compared with those in malignant nodules. These results were similar to our DWI results but our ADC values for benign nodules were quantitatively lower.

Also, in the study made by El- Hariri et al. [18], the mean ADC ( $b$-value 0 and $500 \mathrm{~s} / \mathrm{mm}^{2}$ of the benign thyroid nodules were $1.85 \pm 0.24 \times 10^{-3}$ $\mathrm{mm}^{2} / \mathrm{s}$ while the mean ADC of the malignant thyroid nodules was $0.89 \pm 0.27 \times 10^{-3} \mathrm{~mm} / \mathrm{s}$. These were quiet similar to our results. Aydin et al. [19] calculated the ADC values for both malignant and benign nodules as an average results of $b$ factor 200 and $400 \mathrm{~s} / \mathrm{mm}^{2}$ but they also concluded that malignant nodules had significantly lower ADC values than the benign ones also, mean ADC values among the subtypes of malignant nodules had no significant differences. These were similar to $\mathrm{Ab}$ delrazek et al. [20] and Dilli et al. [21] results. This was in agreement with our results. 
In the previous study by Abd elrhamn et al. [22], DW-MRI was performed using $b$ values of 0 , 500 and $1000 \mathrm{~mm}^{2} / \mathrm{s}$. The mean ADC value of benign solitary thyroid nodules ranged from 1.56 to $2.28 \times 10^{-3} \mathrm{~mm}^{2} / \mathrm{s}\left(\mathrm{b}=1000 \mathrm{~s} / \mathrm{mm}^{2}\right)$ and from 1.64 to $2.70 \times 10^{-3} \mathrm{~mm}^{2} / \mathrm{s}\left(b=500 \mathrm{~s} / \mathrm{mm}^{2}\right)$. The mean ADC value of malignant solitary thyroid nodules ranged from 0.54 to $1.47 \times 10^{-3} \mathrm{~mm}^{2} / \mathrm{s}$ $\left(b=1000 \mathrm{~s} / \mathrm{mm}^{2}\right)$ and from 0.61 to $1.56 \times 10^{-3} \mathrm{~mm}^{2} / \mathrm{s}$ $\left(b=500 \mathrm{~s} / \mathrm{mm}^{2}\right)$. They found a significant difference between benign and malignant solitary thyroid nodules $(p=0.001)$.

According to Le Tuan Linh et al. [23] who reported that when DWI with b500, ADC value of $1.7 \times 10^{-3} \mathrm{~mm}^{2} / \mathrm{s}$ was used as a cut-off value for the differentiation of benign from malignant thyroid nodules, the accuracy was $87.1 \%$ and specificity $90.79 \%$.

In Shi et al. [24] study, the majority (65\%) of malignant thyroid nodules showed slightly hyperintense, and the majority (69\%) of benign nodules were hyperintense on DWI $(p<0.01)$. The ADC values were lower in the thyroid cancer than in the adenoma and nodular goiter $(p<0.05)$. When the factor was $500 \mathrm{~s} / \mathrm{mm}$, an ADC value of $1.704 \mathrm{X}$ $10^{-3} \mathrm{~mm} / \mathrm{s}$ can be threshold differentiating malignant from benign nodules, with $92 \%$ sensitivity, $88 \%$ specificity, and $87 \%$ accuracy. This was similar to the current study as the ADC values of $1.3 \mathrm{X}$ $10^{-3} \mathrm{~mm} / \mathrm{s}$ was used a cut-off to differentiate benign from malignant thyroid nodules with the sensitivity, and specificity were $100 \%$ and $88.9 \%$ respectively.

Our results were not in the same line with Mutlu et al. [17] who found in their study that the sensitivity, specificity, PPV, Negative Predictive Value (NPV) and accuracy rates for ADC values in distinguishing between benign and malignant thyroid nodules were calculated as $80 \%, 97 \%, 80 \%, 97 \%$ and $96 \%$, respectively for $b$-values 50,400 and $1000 \mathrm{~s} / \mathrm{mm}^{2}$ when using the cutoff value of $1.0 \mathrm{X}$ $10^{-3} \mathrm{~mm} / \mathrm{s}$.

Schueller-Weidekamm et al. [25] investigated the DWI results of cold solitary nodules in 25 cases. Contrary to previous studies, they reported higher ADC values for malignant nodules than benign ones. They found that the ranges of the ADC values ( $b$-value of 800 ) for carcinoma were $2.43-3.037 \times 10^{-3} \mathrm{~mm} / \mathrm{s}$, adenoma 1.626-2.233 X $10^{-3} \mathrm{~mm}_{-3} / \mathrm{s}$, and normal parenchyma $1.253-1.602$ $\mathrm{X} 10^{-3} \mathrm{~mm} / \mathrm{s}$ and showed no overlap. When an ADC value of 2.25 or higher was used for predicting malignancy, the highest accuracy was $88 \%$, with $85 \%$ sensitivity \& $100 \%$ specificity. According to another report for Schueller-Weidekamm et al. [26], ADC values of 35 cold solitary nodules, the median ADC values for carcinoma and adenoma were $2.73 \times 10^{-3} \mathrm{~mm}^{2} / \mathrm{s}$ and $1.93 \times 10^{-3} \mathrm{~mm} / \mathrm{s}$, respectively. They found that ADC values of 2.25 $X 10^{-3} \mathrm{~mm} / \mathrm{s}$ or higher proved to be the cut off value for differentiating between benign and malignant cold thyroid nodules, with an accuracy of $88 \%$, a sensitivity of $85 \%$, and a specificity of $100 \%$. According to their comment, however, due to restricted diffusion capacity (lower ADC value) due to hypercellularity found in a malignant tissue, thyroid carcinoma cannot be compared with other malignancies, as the cellular components depend on the macrofollicular production of thyroglobulin, which results in an unrestricted diffusion capacity. They also stated that the presence of microcalcifications may influence the DWI and signal intensities.

In contrast to our results, Schueller-Weidekamm et al. [26] using b value 800 in their study on cold thyroid nodules found, low ADC values for adenomas $\left(1.93 \times 10^{-3} \mathrm{~mm}^{2} / \mathrm{s}\right)$ and high ADC values in thyroiditis and thyroid carcinomas $\left(2.73 \times 10^{-3}\right.$ $\mathrm{mm}^{2} / \mathrm{s}$ ). But in most recent studies that support our study results, ADC values for malignant nodules were not as high as those reported by SchuellerWeidekamm et al. [26].

Different studies showed variation in the cutoff values for predicting thyroid carcinoma, so, each MRI unit should determine the exact threshold value for predicting malignancy in thyroid nodules as there are variations in MRI systems, coils and pulse sequences [27].

Strengths and weakness of the current study, in spite of small sample of the study, there are some strength. Firstly, we found that the mean $\mathrm{ADC}$ values of benign and malignant nodules done by b- 800 and b- 1000 are statistically significantly higher than those done by b-500, so we recommend the use of b-1000 in the evaluation of solitary thyroid nodule to establish a high diagnostic tool in differentiating benign from malignant ones. Secondly, we thought that the difference in results that Schueller-Weidekamm et al. [25], and SchuellerWeidekamm et al. [26], reported is probably related to their technique, which might have affected their accurate sampling with ROI. In their studies, they used a 1-T MRI unit which had relatively lower image quality and obtained DWI in sagittal planes with $b$-values of 0 and $800 \mathrm{~s} / \mathrm{mm}^{2}$. However, in our study, we used a 1.5-T MRI unit which had relatively higher image quality and obtained DWI in axial planes with b values of 800 and $1000 \mathrm{~s} / \mathrm{mm} 2$. 
We recommend using at least a 1.5-T MRI unit and obtain axial images while placing ROI and ADC calculation. Thirdly, in our study, the ADC values of the nodules were compared with the normal thyroid gland tissue.

In conclusion, this study is one of the attempts in the literature to differentiate benign and malignant thyroid nodules using DWI. Our preliminary results showed that DWI provides very useful and promising imaging to evaluate the nature of a thyroid nodule. Even these results may have a role in the selection of nodules that are going to undergo FNAC. But although these are promising results, further investigations are needed with larger patient groups.

\section{References}

1- SALABè G.B.: Pathogenesis of thyroid nodules: Histological classification? Biomed Pharmacother, 55.1: 3953, 2001.

2- KING A.D.: Imaging for staging and management of thyroid cancer. Cancer Imaging, 8: 57-69, 2008.

3- RABER W., KASERER K., NIEDERLE B., et al.: Risk factors for malignancy of thyroid nodules initially identified as follicular neoplasia by fine-needle aspiration: Results of a prospective study of one hundred twenty patients. Thyroid, 10: 709-12, 2000.

4- SUMMARIA V., RUFINI V., MIRK P., et al.: Diagnostic imaging of differentiated thyroid carcinoma [in English and Italian]. Rays., 25: 177-90, 2000.

5- SOLBIATI L., OSTI V., COVA L., et al.: Ultrasound of thyroid, parathyroid glands and neck lymph nodes. Eur. Radiol., 11: 2411-24, 2001.

6- HAUGEN B.R., ALEXANDER E.K., BIBLE K.C., DOHERTY G.M., MANDEL S.J., NIKIFOROV Y.E., et al.: American thyroid association management guidelines for adult patients with thyroid nodules and differentiated thyroid cancer: The American thyroid association guidelines task force on thyroid nodules and differentiated thyroid cancer. Thyroid, 26: 1-133, 2016.

7- NODA Y., KANEMATSU M., GOSHIMA S., KONDO H., WATANABE H., KAWADA H. and BAE K.T.: MRI of the thyroid for differential diagnosis of benign thyroid nodules and papillary carcinomas. Am. J. Roentgenol., 204: W332-W335, 2015.

8- SRINIVASAN A., DVORAK R., PERNI K., ROHRER S. and MUKHERJI S.K.: Differentiation of benign and malignant pathology in the head and neck using 3T apparent diffusion coefficient values: Early experience. Am. J. Neuroradiol., 29: 40-4, 2008.

9- RAZEK A.A., SADEK A.G., KOMBAR O.R., et al.: Role of apparent diffusion coefficient values in differentiation between malignant and benign solitary thyroid nodules. AJNR Am. J. Neuroradiol., 29: 563-8, 2008.

10- ERDEM G., ERDEM T., MUAMMER H., MUTLU D.Y., FIRAT A.K., SAHIN I. and ALKAN A.: Diffusionweighted images differentiate benign from malignant thyroid nodules. J. Magn. Reson. Imaging, 31: 94-100, 2010.

11- TESSLER F.N., MIDDLETON W.D., GRANT E.G., HOANG J.K., BERLAND L.L., et al.: ACR Thyroid Imaging, Reporting and Data System (TI-RADS): White Paper of the ACR TI-RADS Committee. Journal of the American College of Radiology: JACR, 14: 587-95, 2017.

12- KIM S., LOEVNER L., QUON H., et al.: Diffusionweighted magnetic resonance imaging for predicting and detecting early response to chemoradiation therapy of squamous cell carcinomas of the head and neck. Clin. Cancer Res., 15: 986-94, 2009.

13- GUPTA R.K., CLOUGHESY T.F., SINHA U., et al.: Relationships between choline magnetic resonance spectroscopy, apparent diffusion coefficient and quantitative histopathology in human glioma. J. Neurooncol., 50: 21526, 2000.

14- KATAYAMA M., MASUI T., KOBAYASHI S., ITO T., SAKAHARA H., NOZAKI A., et al.: Diffusion-weighted echo planar imaging of ovarian tumors: Is it useful to measure apparent diffusion coefficients? J. Comput. Assist. Tomogr., 26: 250-6, 2002.

15- SUMI M., SAKIHAMA N., SUMI T., et al.: Discrimination of metastatic cervical lymph nodes with diffusion-weighted MR imaging in patients with head and neck cancer. AJNR Am. J. Neuroradiol., 24: 1627-34, 2003.

16- BOZGEYIK Z., COSKUN S., DAGLI A.F., et al.: Diffusion-weighted MR imaging of thyroid nodules. Neuroradiology, 51: 193-8, 2009.

17- MUTLU H., SIVRIOGLU A.K., SONMEZ G., et al.: Role of apparent diffusion coefficient values and diffusionweighted magnetic resonance imaging in differentiation between benign and malignant thyroid nodules. Clin. Imaging, 36: 1-7, 2012.

18- EL-HARIRI M.A., GOUHAR GHADA K., SAID NAGWA S., et al.: Role of diffusion-weighted imaging with ADC mapping and in vivo 1H-MR spectroscopy in thyroid nodules. Egypt J. Radiol. Nucl. Med., 43: 183-92, 2012.

19- AYDIN H., KIZILGÖZ V., TATAR I., et al.: The role of proton MR spectroscopy and apparent diffusion coefficient values in the diagnosis of malignant thyroid nodules: Preliminary results. Clin. Imaging, 36: 323-33, 2012.

20- ABDEL RAZEK A.A.K., SADEK A.G., KOMBAR O.R., ELMAHDY T.E. and NADA N.: Role of apparent diffusion coefficient values in differentiation between malignant and benign solitary thyroid nodules. American Journal of Neuroradiology, 29 (3): 563-8, 2008.

21- DILLI A., AYAZ U.Y., CAKIR E., et al.: The efficacy of apparent diffusion coefficient value calculation in differentiation between malignant and benign thyroid nodules. Clin. Imaging, 36: 316-22, 2012.

22- ABDEL-RAHMAN H.M., ABOWARDA M.H. and ABDEL-AAL S.M.: Diffusion-weighted MRI and apparent diffusion coefficient in differentiation of benign from malignant solitary thyroid nodule. The Egyptian Journal of Radiology and Nuclear Medicine, 47 (4): 1385-90, 2016.

23- Le TUAN LINH, NGUYEN NGOC CUONG, TRAN VIET HUNG, et al.: Value of Diffusion Weighted MRI 
with Quantitative ADC Map in Diagnosis of Malignant Thyroid Disease. Diagnostics, 9 (129): 1-8, 2019.

24- SHI H.F., FENG Q., QIANG J.W., LI R.K., WANG L., and YU J.P.: Utility of diffusion-weighted imaging in differentiating malignant from benign thyroid nodules with magnetic resonance imaging and pathologic correlation. Journal of Computer Assisted Tomography, 37 (4): 505-10, 2013.

25- SCHUELLER-WEIDEKAMM C., KASERER K., SCHUELLER G., et al.: Can quantitative diffusion-weighted MR imaging differentiate benign and malignant cold thyroid nodules? Initial results in 25 patients. AJNR Am J. Neuroradiol., 30: 417-22, 2009.

26- SCHUELLER-WEIDEKAMM C., SCHUELLER G., KASERER K., et al.: Diagnostic value of sonography, ultrasound-guided fine-needle aspiration cytology, and diffusion-weighted MRI in the characterization of cold thyroid nodules. Eur. J. Radiol., 73: 538-44, 2010.

27- CHEN L., XU J., BAO J., HUANG X., HU X., XIA Y. and WANG J.: Diffusion-weighted MRI in differentiating malignant from benign thyroid nodules: A meta-analysis. BMJ Open, 6: 841-3, 2016.

\section{فاعلية التصوير بالرنين المغناطيسى بالانتشار الموزون الماند فى عقيدات الغدة الدرقين العنية}

الانتشار الواضداف: تقييم فعالية التصوير بالرنين المغناطيسى المونفن فى الانتشار بين العقيدات الدرقية الحميدة والخيئة التى تقارن نتائج معامل

المرضى والطرق: أجريت هذه الدراسة على + ا مرضى يعانون من العقيدات الدرقية (المهيمنة الصلبة أو مختلة الكيسى) للغدة الدرقية

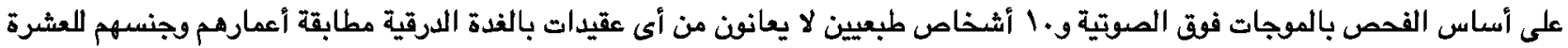

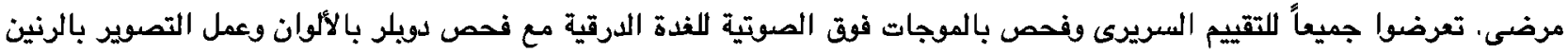

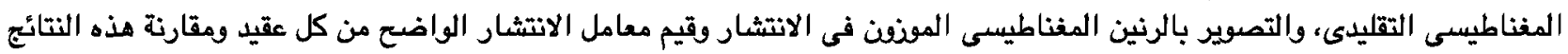
مع نتائج التشريع المرضيى.

النتائج: بلغت قيمة حساسية وخصوصية فحص الرنين المغناطيسى المونفن فى الانتشار فى التفرقة بين العقيدات الحميدة والخبيثة للغدة

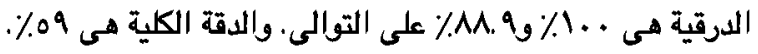

الخلاصدة: أظهرت النتائج الأولية أن التصوير بالرنين المغناطيسى المهنف فى الانتشار يوفر تصويراً مفيداً واعداً لتقييم طبيعة العقيدات

الدرقية وفى التفرقة بين العقيدات المميدة والخبيثة. 